\title{
Mediating science and nature: representing and consuming infant formula advertising in China
}

\section{Qian Gong}

University of Leicester

\section{Peter Jackson}

University of Sheffield

\begin{abstract}
:
This paper analyses the representation and consumption of infant formula advertising on Chinese television, following the baby milk scare in 2008. Drawing on the concepts of 'encoding/decoding' and 'circuit of culture', the paper investigates how the Chinese dairy industry encodes the messages of food safety and quality in their advertisements and how parents decode the messages as part of their risk management strategies. The paper focuses on two moments - representation and consumption - in the 'circuit of culture'. Combining a critical analysis of advertising imagery with focus group and interview regarding its consumption, the paper suggests that the dairy industry juxtaposed images of science and nature to mediate messages about the quality and safety of infant formula. Findings show that Chinese consumers decode these messages based on their previous experience and knowledge, exhibiting considerable ambivalence about the advertising of infant formula and reflecting significant anxiety about the product's quality and safety. Both the representation and consumption of the advertising messages should be understood within the wider social and political context including the prevalent medicalization of childcare which accompanied recent neoliberal reforms and the lax regulation of health product advertising in China. The paper concludes that, in the absence of independent medical advice, affordable medical treatment and adequate government regulation, infant formula companies can make illfounded health claims for their products and employ dubious promotional tactics.
\end{abstract}

Keywords: encoding, decoding, circuit of culture, infant formula, food scares, TV advertising, science, nature, China

\section{Introduction}

In the context of our current work on consumer anxieties about food, this paper analyses how the Chinese dairy industry encodes messages of food safety and quality in their infant formula (baby milk) advertisements and how parents decode these messages as part of their daily risk management strategies following the 'food scare' of 2008. ${ }^{1}$ Unlike many food scares, the contamination of infant formula was not accidental. It was caused by unscrupulous merchants watering down milk in order to increase its volume, adding melamine in order artificially to enrich its protein content. The issue caused an international scandal culminating in hundreds of babies being hospitalized with kidney problems, several 
of whom died. Having initially tried to cover up the problem, the authorities later prosecuted many of those involved, several of whom now face long prison sentences and two of whom were executed. One of the main companies involved in the scandal, Sanlu, went out of business and numerous dairy company employees and municipal officials lost their jobs. Following the food scare, consumers manifested a high level of distrust of the government sectors that were in charge of food safety regulation and supervision, as well as the Chinese dairy industry of which some 22 companies were implicated in the infant formula scandal. (Xinhua News Agency, 2008; Qiao, et al. 2010; Zhang, et al. 2010). The Chinese dairy industry then faced serious problems restoring consumer confidence in local (domestic) brands as the sale of imported brands soared despite their significantly higher prices (authors, in press).

This paper explores TV advertising campaigns after the 'food scare' as dairy companies tried to restore consumer confidence. The paper examines the content of TV advertisements for Chinese-produced infant formula and analyses how images of science and nature were encoded to mediate messages of food safety and quality. We also use focus groups and interviews with parents and grandparents to understand how consumers decode such messages. ${ }^{2}$ We begin by outlining the role of advertising in contemporary China and the capacity of audiences to 'make sense' of media representations. We then outline our research methods before turning to the core of our analysis, examining how images of science and nature were artfully combined in mediating messages about the quality and safety of infant formula in the wake of the 2008 crisis. Our evidence suggests that Chinese consumers exhibit considerable ambivalence about infant formula advertising as they decode these messages based on previous experience and knowledge. Both the representation and consumption of the advertising messages should be understood within the wider social context including the prevalent medicalization of childcare in China which has accompanied recent neoliberal reforms. The paper concludes that, in the absence of independent medical advice and affordable medical treatment, infant formula companies can make ill-founded health claims for their products and employ dubious promotional tactics.

\section{Advertising in contemporary China}

After the economic reforms and Open Door Policy introduced in the late 1970s, state planning in China began to give way to a more market-orientated economy. Following two decades of material deprivation and anti-consumerism, advertising began to play a more prominent role in communicating product information to consumers. ${ }^{3}$ Since the Chinese authorities allowed newspapers and television to carry domestic and international advertisements for the first time in 1979 (Anderson, 1981), ${ }^{4}$ the Chinese consumer market, including the advertising industry, has expanded rapidly with growing Gross Domestic Product per capita (GDP), World Trade Organization (WTO) accession and increasing disposable incomes among the middle class (Cheong, et al., 2011; Paek and Pan, 2004; Wang, 2000, 2003, 2008; Zhou, et al., 2002). The growth of the advertising industry has been particularly boosted by foreign advertisers and multinational advertising agencies (Hong, 1994; Nelsen, 2006; Sinclair, 2008). 
While the consumer and advertising markets kept expanding with increased urbanisation and globalisation, patterns of Chinese consumption have also changed. ${ }^{5}$ Consumption has shifted from domestic utilities (e.g. washing machines) to personal goods and services with more symbolic value (Curtis et al. 2007; Davis and Sensenbrenner, 2000; Hopkins 2010; Klein 2006; Yan, 1997). While some scholars believed that consumption was an economic driving force in the 1980s and 1990s (Latham 2006), others were critical of consumerism as it encouraged materialism and money-worship in China (Zhou 2008). Coinciding with these changes, advertising techniques have also become more sophisticated. Direct, hard-sell and rational approaches are increasingly being replaced by indirect, soft-sell and image-orientated appeals (Chan, 1997) and variations of the 'rational' and 'emotional' approaches are being flexibly used based on the demographic, regional and socio-economic background of Chinese consumers. ${ }^{6}$ Complex advertising campaigns based on identity formation and symbolic values have become effective particular among young and urban consumers (Cheong, et al., 2011; Ferry, 2010; Paek and Pan, 2004; Zhou and Hui, 2003). On the other hand, some literature has demonstrated that audiences are becoming increasingly sophisticated in their reading of media messages and consumer responses are becoming increasingly diverse (Donald et al.2002; Zhao 2008).

\section{Encoding/Decoding and the 'Circuit of Culture'}

While earlier work on the cultural politics of advertising focused predominantly on the analysis of media representations (including the visual and verbal content of advertising images), more recent work has included other aspects of the 'circuit of culture' including the inter-connection between different moments of representation, identity, production, consumption and regulation (du Gay, et al., 1997). The 'circuit of culture' model has provided a theoretical and methodological framework to analyse the 'biography' of cultural texts and artefacts (du Gay et al., 1997). In this paper, we engage with the 'circuit of culture' model and focus particularly on the 'representation' and 'consumption' moments. We also use the concept of 'encoding/decoding' (Hall, 1977; Morley, 1980; Schroder, 2000) which proposes more complex understandings of how viewers and audiences make sense of media texts and images, especially how their pre-existing knowledge, experiences, beliefs and background can influence the ways they decode the messages. Audience studies, including the work of Ang (1991, 1996), Morley (1992) and others (e.g. Silverstone \& Hirsch 1992) directed attention to the domestic context of media consumption and reached more positive conclusions about the capacity of audiences and viewers to critically engage with mass media than was assumed in earlier theories of media reception where audiences were conceived of in more passive terms.

\section{Research methods}

Previous research shows that TV and print media (including newspapers, magazines and scientific publications) are the preferred advertising media for infant formula products (Matthews et al., 2009) and it is well established that advertising investment in television has far exceeded that in other media platforms such as newspapers, magazines, radio, outdoor billboard and the Internet (Aegis Media, 2010). In 2006, TV advertising expenditure took up over $80 \%$ of the total advertisement expenditure in China (Nielsen Media Research, 2006). 
The above statistics show that TV advertising has the widest reach among Chinese consumers and it is the most visible dimension of producer-consumer communication in our study of the representation and consumption of food safety messages.

Infant formula advertisements were collected from Adtopic.net, the most comprehensive advertising video website for industry and academic use in China. The videos of infant formula advertisements were retrieved from a keyword search on the website search engine and filtered again through manual search. ${ }^{7}$ In total 69 advertisements from 32 brands were collected, covering a two-and-a-half year period from March 2008 to September 2010. We analysed advertisements broadcast before and after the melamine scandal (September 2008) to compare whether the most salient themes of the advertisements were affected.

The most notable themes of the advertisements were identified through repeated viewings by the authors. These themes were then developed into a fuller coding schema with 19 values. ${ }^{8}$ Each advertisement was coded using the Statistical Package for the Social Sciences (SPSS) for a preparatory content analysis, to describe the frequency of the themes to 'establish significance not statistically, but in the sense of importance' (Schegloff in Wood and Kroger, 2000: 138). ${ }^{9}$ In the pre-analysis, we found that the themes of nature, science and technology, and assurance were more salient during stage 2 and 3 (one year after the melamine scandal), and other popular themes were more equally distributed in all stages (see Table 1). Visual images and texts relevant to these themes were systematically contrasted and compared. In this paper we focus on the themes of 'nature' and 'science' in the most representative advertisements (for Wondersun and Firmus) including some comparative analysis with a leading international manufacturer (Dumex).

\begin{tabular}{|c|c|c|c|c|c|c|c|}
\hline Theme & $\begin{array}{l}\text { Nature } \\
\text { (Farm, } \\
\text { Cow, } \\
\text { etc.) }\end{array}$ & \begin{tabular}{|c|} 
Science \\
and \\
Technology
\end{tabular} & $\mid \begin{array}{c}\text { Assurance of } \\
\text { safety and } \\
\text { quality } \\
\text { (institutional, } \\
\text { organisation, } \\
\text { etc.) }\end{array}$ & $\begin{array}{c}\text { Assurance } \\
\text { of safety } \\
\text { and } \\
\text { quality } \\
\text { (Personal } \\
\text { testimony) }\end{array}$ & $\begin{array}{l}\text { Aspiration } \\
\text { (Success, } \\
\text { achievement, } \\
\text { etc.) }\end{array}$ & $\begin{array}{l}\text { Nutritional } \\
\text { and health } \\
\text { Benefits }\end{array}$ & $\begin{array}{l}\text { Foreign } \\
\text { Ownership }\end{array}$ \\
\hline Stage 1 & 0 & 2 & 0 & 0 & 5 & 9 & 2 \\
\hline Stage 2 & 6 & 9 & 6 & 4 & 6 & 6 & 3 \\
\hline Stage 3 & 2 & 9 & 7 & 3 & 5 & 1 & 3 \\
\hline Stage 4 & 1 & 2 & 1 & 0 & 5 & 11 & 2 \\
\hline Stage 5 & 0 & 4 & 1 & 0 & 2 & 4 & 2 \\
\hline Total & 9 & 26 & 15 & 7 & 23 & 31 & 12 \\
\hline
\end{tabular}

Table 1: Frequency of most notable themes across five stages

Stage 1: March-August 08 ( $1 \frac{1}{2}$ year before the scandal)

Stage 2: September 2008 - February 2009 ( $1 / 2$ year since the scandal)

Stage 3: March 2009 - August 2009 (1 year since the scandal)

Stage 4: September 2009 to February 2010 (11/2 years since the scandal)

Stage 5: March 2010 - September 2010 (2 years since the scandal)

In addition to the analysis of advertising content (texts and images) we also use focus groups and interviews with parents and grandparents to investigate how they understand the 
advertising campaigns which emphasized the messages of 'science' and 'nature' to assure food safety. Our focus group discussions with parents and grandparents of babies and young children (aged 3 months to 2 years) in Chengdu, the capital of Sichuan province, were conducted in February and March 2010 and March 2011. We asked open-ended questions about our respondents' baby-care experiences, their understanding of infant formula advertisements, their sources of information regarding baby care, their feeding practices and perceptions of the safety of baby food now and prior to 2008. Open-ended questions allowed respondents to explore their personal experiences as well as other socio-cultural and politicaleconomic issues to explain their decoding of food safety and quality messages in the advertisements. Twelve focus groups were conducted, lasting between 40 and 90 minutes. They were internally homogeneous in terms of role and social status (e.g. mothers from 'middle-class and above' neighbourhoods, grandmothers from 'low-income' neighbourhoods etc.), with 4 to 6 participants in each group. ${ }^{10}$ Focus groups were audio and video taped, transcribed in full, translated from Chinese to English and coded using N.Vivo8 (a qualitative analysis software package). The project received ethical approval from the University of Sheffield in January 2010.

\begin{tabular}{|c|c|l|l|}
\hline $\begin{array}{c}\text { Group } \\
\text { No. }\end{array}$ & $\begin{array}{c}\text { No. of } \\
\text { participants }\end{array}$ & \multicolumn{1}{|c|}{ Carer group } & \multicolumn{1}{|c|}{ Social status } \\
\hline 1 & 6 & Mothers & Middle-class and above \\
\hline 2 & 4 & Mothers & Low-income \\
\hline 3 & 6 & Grandparents & Low-income \\
\hline 4 & 5 & Grandmothers & Low-income \\
\hline 5 & 5 & Mothers & Middle class and above \\
\hline 6 & 4 & Grandmothers & Middle class and above \\
\hline 7 & 5 & Mothers/grandmothers & Middle class and above \\
\hline 8 & 4 & Mothers & Middle class and above \\
\hline 9 & 5 & Grandmother & Low-income \\
\hline 10 & 5 & Parents & Low-income \\
\hline 11 & 4 & Mothers & Middle class and above \\
\hline 12 & 4 & Mothers & Middle class and above \\
\hline
\end{tabular}

Table 2: Composition of the focus groups

\section{Narrating nature}

This section analyses representations of 'nature' in advertisements by infant formula companies and how they were consumed by parents and grandparents in China using images from TV advertisements and focus group discussions. After the infant formula scandal in 2008, many dairy companies produced TV advertisement campaigns to try to reassure their consumers of the safety and quality of their products. These campaigns took advantage of the relaxed regulation of infant formula advertising in China, ${ }^{11}$ using a variety of appeals to restore consumer confidence. In some advertisements (e.g. Nanshan), staff members from the dairy company (including the firm's CEO, a lab worker and a buyer) testified to the safety of the company's products, claiming that they feed them to their own children. Other companies resorted to more conventional strategies, focusing on the scientific claims and alleged health benefits of their products. In many cases, idyllic images of 'nature' (including 
idealized images of dairy farms) are juxtaposed with images of 'science' (including labcoated scientists and their laboratories).

For example, in a 15-second advertisement that Wondersun broadcast on a national television channel (CCTV 1) on 6 March 2009, a male voice-over asks 'How do we make good infant formula?' While the voice-over spells out 'location, milk source and formula', the screen shows a visual combination of all three elements (Figure 1). ${ }^{12}$ The voice-over continues, 'All these are very important, but what is more important is conscience'. The screen then switches to a group of Chinese and Western scientists in white lab coats, standing together with their hands across their chests (Figure 2). ${ }^{13}$ The advertisement finishes by flashing up a series of pictures of smiling babies and showing several tins of Wondersun infant formula, while the voice-over says 'For 45 years, Wondersun has insisted on making good infant formula with conscience'.

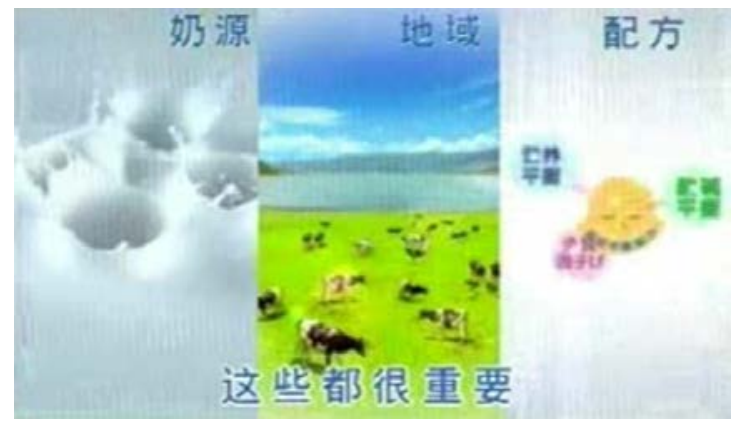

Figure 1: Wondersun advertisement 1

Image (C) Wondersun (reproduced with permission)

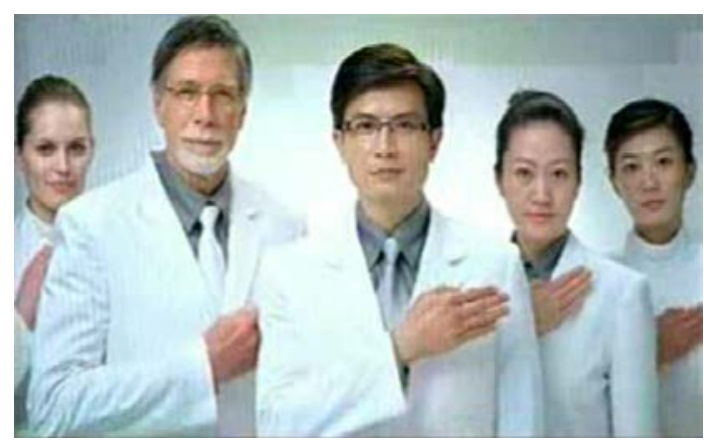

Figure 2: Wondersun advertisement 2

Image (C) Wondersun (reproduced with permission)

The emphasis on 'conscience' (‘良心’) draws a distinction between Wondersun and other dairy companies that were implicated in the infant formula scandal who were widely criticized for their lack of business ethics and conscience by the media. As one of the melamine-free brands, Wondersun benefited from the scandal and jumped from a third-tier brand to a second-tier brand in the Chinese dairy market (interview with Wondersun sales representative in charge of North-East China, 2010). But even though the contamination 
occurred at multiple points in the production chain (milk collection at the farm, storage at milk stations and transportation to dairy manufacturers), this advertisement only addresses the first link in the chain (dairy farms). The 'location' image reassures consumers that Wondersun's dairy farms are located in green, open and clean ('natural') fields. The farm in this advertisement is portrayed as an open green field, with sporadic grazing cows, adjacent to a lake and mountains under a blue sky. The complete absence of human figures or humanrelated subjects foregrounds conventional rural signifiers such as green grass and blue sky, invoking a romanticization of the rural and idealized representations of nature.

The way that nature is depicted as undisturbed and pristine has its roots in the Western romantic tradition (Paterson, 2006). Narratives of being 'pure', 'natural' and 'green' were present in food advertisements in the early $20^{\text {th }}$ century (Domosh, 2003) and have become more prominent in the context of contemporary agri-food systems with their characteristic separation of food production and consumption (Dimitri and Oberholtzer, 2010; Hollander, 2003; Wilk, 2006). The growing distance between producers and consumers in globalized food chains, as well as outbreaks of food scares due to unsustainable food production systems, has created an imaginary space for food and beverage companies to sell their products, charging premium prices based on these imagined geographies. Consumer anxieties about unknown provenance, exacerbated by high-profile food scares, have also made 'location', 'place' and ‘origin' crucial aspects of food safety and signifiers of quality in food advertising in China.

The emerging narrative of 'nature' in food advertising is associated with the growing number of affluent middle-class consumers in urban China and their increasing embrace of 'natural' food in their daily diet. 'Natural' food (e.g. coarse-grained cereals) that was traditionally consumed in rural areas is now increasingly being recognized as healthy, safe and natural among urban consumers. This is in accordance with the revival of shi yang ('proper diet'), a dimension of medicinal food in yang sheng ('life nurturance' or 'self-cultivation') in traditional Chinese Taoist culture (Farquhar, 2002: 51; Liu, 2004: 713). In this ancient way of using medicine and food, human beings are a 'microcosmic reflection of a much greater whole that encompasses all forces of nature' (Holland, 1997: 9). Such foods are thought to regulate various biological functions and bodily organs, nurturing human vitality (Liu, 2004: 713). The interrelations of nature, body and food in this tradition are recreating the foundations for shi yang for the affluent middle classes who are increasingly investing in food, health and spiritual well-being.

The consumption of coarse 'natural' food among the growing urban middle classes has been referred to as a 'romantic reappraisal' of Chinese rural tradition (Griffiths et al., 2010). ${ }^{14}$ In their analysis of middle class Chinese people's visits to rural gardens located close to major cities, Griffiths et al. (2010) argue that the desire for going back to nature has been associated with urban migrants' earlier experiences in rural China. As rurality is often associated with the suffering of middle-aged middle-class consumers who experienced their adolescence during the Cultural Revolution, Hubbert (2007: 95) argues that eating coarse food which was common during that period fulfils strongly 'cathartic functions of public memorialization'. 15 The meanings associated with the narrative of 'nature' in China embody not only nostalgia at 
the personal or domestic level, but also a more politicized collective reflection of a specific historical movement in the public domain. Nonetheless, with China's rapid urbanization and industrialization, there have been rising demands for a more general daily consumption of 'natural' products by many social groups other than the 'educated youth'. The fact that the rural gardens discussed by Griffiths et al. (2010) are flourishing nationwide and that people are willing to pay to enjoy nature (green fields, flowers, fresh air and coarse food) indicates an increasingly romanticized consumption of nature in China that shares many characteristics with the romantic tradition in the West (cf. Williams 1973). ${ }^{16}$

However, the meanings of nature in relation to baby food are quite diverse. There seems to be an inconsistency in the understanding of nature according to different dimensions of child care. While most urban baby-carers envision safer and higher quality food (such as freerange eggs and vegetables grown with less fertilizer) coming from more natural environments in rural areas (authors, in press), many parents also expressed their concern that the therapeutic diets in shi yang may not be suitable for young children and that such diets may do more harm than good. Moreover, when asked if the images of nature in these advertisements would affect their decision to choose a particular brand of infant formula, many of our focus group participants considered the images of nature a common feature of such advertisements with little impact on their choice of brand. For example, one group discussed their reasoning as follows:

I have seen this too much.

Too much. They all have it, cows and meadows. [Referring to specific brands] Yili and Mengniu both have it (Parents from low income background, group 10).

Like these focus group participants, many others thought that the images of nature in these advertisements were unlikely to command their attention. This can be partly explained by widespread public distrust of deceptive and misleading advertisements in China (Hong, 1994). The most influential factor in their decision-making, according to our participants, was their babies' experience of using the products. When asked to elaborate on this, participants talked about the physical condition of individual children when choosing between different brands, e.g. brand $\mathrm{X}$ causes indigestion for this baby but not brand $\mathrm{Y}$. The usually paired adjectives 'foreign' ${ }^{17}$ and 'better' in describing infant formula seemed to appear less frequently at this point and a process of decommodification or recontextualisation seems to be occurring in which greater emphasis is placed on use-value over exchange-value (cf. Sayer, 2001), assessing how each brand may be suitable for individual babies. This shows a more complex set of criteria in baby food consumption than consumption being governed solely by symbolic values (being foreign) as indicated in previous discussion groups. ${ }^{18}$ 'Being foreign' only provides a framework for new parents to select infant formula products with foreign ownership as their first choice. Their final selection is combined with other 'rules of thumbs' (e.g. whether the baby likes the taste of it, whether the formula causes dry mouth or constipation) that are 'congruent with cultural frameworks that prioritize a number of other attributes such as taste and wholesomeness' (Green et al., 2003: 50). At this point, the reference to nature, although highly valued in relation to solid baby food, has not been linked to the images of nature in the infant formula advertisements to create a brand preference. 
The ambivalence exhibited by parents was also related to their differentiation of 'nature' in Chinese and foreign contexts, their childhood experience of rurality and nature, and their rationalization of the geographical locations of food production. Although the images of 'nature' in the advertisements were unlikely to directly affect the decision of selecting formula brands (as demonstrated above), parents did use the images of genuine green pasture and blue sky as criteria to judge the location of food production in general terms. The criteria were particularly applicable to foreign brands that were thought to be produced in truly unpolluted and natural environments. After expressing their distrust of images of 'nature' in the Chinese infant formula adverts, one father said:

New Zealand has the best milk source in the world.

Researcher: Why do you think so?

It's less polluted there, and there are very few people too. (Parents from low income background, group 4)

Childhood experiences in rural village among some parents also shaped their decoding of 'nature'. While most parents criticized the general 'natural' images used in Chinese infant formula advertisements as untrue representations, some recalled images of 'nature' from their own childhood experience in villages and used those nostalgic images of rurality to support the safety and quality of local infant formula products:

Look at that blue sky and white cloud in that ad...

Chengdu has no blue sky and white cloud.

My husband chose Hongya [a small county $120 \mathrm{~km}$ from Chengdu] infant formula for my little boy. He [husband] grew up there, and he knows the pasture there. The environment [there] is better and the air is fresher. (Parents from low income background, group 10)

Others parents shared less romantic and nostalgic sentiments, and took a more 'rational' approach towards these images in terms of the location and economics of production. One mother said the images promoted in the advertisements provided her with a reference point, but other criteria such as having a safety certificate were also applied when she decided to choose a domestic brand which was considered risky and almost unacceptable by most of the focus group participants:

I use the images in the ad as a reference. I'm thinking about using Wondersun, because it is from Helongjian where there is good pasture and environment. I know for a fact that there is good, pure raw milk that doesn't have to travel thousands of kilometres to other parts of China. There should be plenty of milk sources for local dairy companies. If the formula was produced right next to the dairy farm, it should be safe. (Parents from middle class and above background, group 8)

This mother drew on her knowledge of the 2008 'food scare' (which resulted from demand outstripping production) to interpret the message. In addition, her explanation also demonstrates her understanding of how food safety risks increase as the length of the supply 
chain increases. Knowledge of the cost of milk production helps her critically decode the messages in the advertisements, reaching an alternative perspective on food safety. Her decoding of the messages also demonstrates a consumer-citizen dimension in that she was actively searching for and verifying information from the advertisements, and using an ethical assessment of 'food miles' to evaluate the way that food was produced.

Similar inconsistency in the understanding of nature is demonstrated in contexts where nature is considered as a holistic environment for children to grow up. Following the discussion of safer food in rural areas, a group of grandmothers originally from rural China started to explore the idea of raising their grandchildren there in order for them to benefit from fresh vegetables and free-range eggs. The group expressed mixed feelings about rurality:

This kid was born in Chengdu. If he goes back [to the rural area] he'll get a rash. Those are red, big, and very itchy. Nasty.

It won't work. He can't get used to the water and soil there.

Researcher: Do you think it is because of the bugs, like mosquitoes that cause the skin problems?

No, it's the water.

The water. Water here [in Chengdu] is disinfected, but it's not there [in the rural area].

That's why, he has no antibody.

My mum gets water from the foot of the mountain. It is cleaner than the tap water here.

It is cleaner.

But he still gets a rash... (Grandmothers from low-income background, group 9)

Water, the most common materialization of nature, is associated with purity (clean water from the foot of the mountain) and peril (giving a nasty rash to children). Consumer perceptions relate to both the romantic side of nature that revitalizes and the dark side of nature that destroys. The rather contradictory understanding of water (cleaner but gives children a rash) also reveals an ambiguous understanding of rurality. Because of the social inequality based on status, class and rural/urban divide in China, our participants from rural areas are stigmatised as backward, provincial and inferior (authors, in press). But as food scares often recur in cities, and food from the rural is increasingly deemed as safer, the rural is re-evaluated in comparison with the urban. The high re-evaluation of the rural, however, is not always consistent - while our participants support the view that the natural environment is associated with 'unproblematic' foods such as meat, fruits and vegetables, they also worried that some aspects of nature such as soil and water may not be suitable for urban-born children.

The above examples show that our participants engaged with the message of nature from various perspectives, reaching different conclusions regarding the safety and quality of infant formula in relation to nature - while some parents reinforced the image of nature in the advertisement with their nostalgic memory of the past, others critically assessed the image with an analysis of the food production chain. Ambiguity in consumers' understanding of 
rurality also underlies conflicting perceptions of water, the materialization of nature, as both pure and perilous.

\section{Selling Science}

In this section, we turn to the representation and consumption of 'science' in the advertisements. In addition to analysing images and evidence from focus groups, we also extend our discussion to the wider social context in which these advertisements are consumed including the medicalization of childcare, prevalent parental anxieties, and neoliberal healthcare reform in China, all of which we argue are relevant to the advertising of infant formula.

In a 30-second advertisement for Firmus infant formula, the production processes are shown in a sequence of frames made up of images and texts. ${ }^{19}$ These frames are accompanied by some gentle piano music. Unlike the Wondersun advertisement (shown in Figures 1-2), in this case images of nature are juxtaposed with images of science, or even seamlessly connected within the same frame, with the blue sky floating above images of an industrial processing plant (the text confirming that 300,000 purifying procedures are used which meet international standards). ${ }^{20}$ After two frames showing lab-coated scientists and another frame of the green earth, the product itself appears in a beaker-like container. In this advertisement, a complex production process has been reduced to two locations: farms and laboratories. The only humans involved in the production process are scientists. Nature and science co-exist harmoniously, with no apparent conflict.

First broadcast in November 2008, this advertisement focuses on farms as a symbol of the safety and quality of the milk. The heart shape made by the group of scientists (in white lab coats) and managers (in dark suits), standing together, could be interpreted as a retort to the lack of business ethics which led to the 2008 infant formula scandal. These few images take up about 20 seconds of the advertisement and are followed by a few frames which show a baby reaching up to a tin of Firmus formula, a mother holding the baby and the baby happily playing with the tin. The message contained in the advertisement is of a highly simplified process of formula production, with a reassuring combination of science and nature, leading inexorably to satisfied babies and contented mothers. Yet, as we have seen, the apparent transcendence of nature and science in such a seamless fashion, involving idealized images of nature and simplified representations of science, does not automatically reassure consumers whose attitudes towards rurality and science are often ambivalent (as demonstrated by our focus group research). In the following paragraphs, we explore the wider context in which these advertisements are consumed. We draw on focus group evidence to show how parents decode the message of 'science', based on their experiences of neoliberal healthcare reforms and the increased medicalization of childcare in China.

Historically, the discourse of science has featured strongly in childcare practices and parenting advice worldwide (Apple, 1987, 2006; Grant, 1998). This discourse fits well with China's national strategy of 'scientific development' and has become increasingly powerful in the current neo-liberal economic context (Harvey, 2005). ${ }^{21}$ Within this context, the state is 
withdrawing from managing pregnancy, birth and childcare, leaving parents to make their own choices in an individualized and commercialized childcare system (Shi, 2009). The financial reform of the public health services in the 1990s further shifted power towards commercialized medical institutions. Attempting to justify the policy, it was argued that the reforms improved the productivity of public health institutions, but they also had many negative consequences. Sharp decreases in medical insurance coverage especially in rural China and increased costs for medical care were among the most notable outcomes ( $\mathrm{Du}$, 2009; Liu and Mills, 2002). ${ }^{22}$ Child immunization services, for example, cost $¥ 2-4$ in the 1980 s, but more than $¥ 10,000$ today. ${ }^{23}$

Resorting to the powerful discourse of 'science', infant formula companies formed an aggressive marketing strategy in the wake of the 2008 scandal, drawing attention to the alleged health benefits of their products based on 'scientific' research. ${ }^{24}$ The same strategy has contributed to a sharp decline in breastfeeding rates in China since the1990s (Gottschang, 2000; Xu et al., 2006). The adoption of 'scientific' childcare practices have also become a coping strategy for many parents regarding their food safety concerns. ${ }^{25}$ The incorporation of micro-nutrients such as vitamins which are given paramount importance in people's daily diet features strongly in the scientific claims of infant formula companies. TV advertisements frequently refer to the use micro-nutrients in promoting the health benefits of their products. They also aggressively exploit the lax regulation of health claims in China. ${ }^{26}$ For example, while few of our focus group participants knew exactly what ARA and DHA are, nearly all of them recognized these allegedly 'must-have' nutrients and believed that they were 'some kind of necessary ingredients for infant formula'. ${ }^{27}$ As noted elsewhere (authors, in press), one grandmother in our consumer focus groups believed that her daughter's breast milk was nutritionally inferior to imported infant formula because the latter contained micro-nutrients like DHA and ARA. And, as we have shown above, while new parents engage critically with the 'nature' narrative employed in infant formula advertisements, they are somewhat less sceptical about the products' alleged scientific benefits, although here too some focus group participants remained ambivalent about the promotional tactics used by some infant formula companies. As one mother reported:

Abbott had this seminar... ${ }^{28}$ they flew a childcare expert from Shanghai to Chengdu to explain the advantages of Abbott products. It's said that he charges $¥ 300$ per hour for consultancy... I went there because I really wanted to learn. I took my pen and notepad... The hall was full [of parents]... He showed us a video like this, followed by a little quiz and the questions were all in the video... ${ }^{29}$ Those who got the questions right got some free infant formula (Mother from lowincome background, group 9).

In this case, the mother's enthusiasm wore off as she attended more seminars and realized that their purpose seemed to be more about promoting infant formula than about disseminating experiences and knowledge of childcare. Another young mother was equally unhappy about her experiences in peer-support group meetings organized by an online mothers' forum: 
I don't know. We have different levels of knowledge, so the conversation doesn't always flow... and the strangest thing is, all of a sudden, a participant turns into a sales representative and starts selling formula to us (Mother from middle class background, group 12).

Their interpretations of the messages of 'science' and 'scientific knowledge' were both influenced by the same suspicion of the problematic promotional tactics - childcare seminars or mothers' forums with a hidden agenda of selling infant formula product. Although these two mothers were able to identify the suspicious promotional tactics, it is important to note that their lack of child-rearing confidence may have drawn them to these events in the first place. As we argued elsewhere, many new parents with varied social status in our focus groups felt uncertain about their childcare skills, especially when they were faced with a plethora of, sometimes conflicting, information from unsanctioned commercial sources. Our focus group research also found that the promotion of the alleged scientific benefits of infant formula, although not overtly endorsed by medical professionals, was tolerated by many maternity wards and community hospitals. ${ }^{30}$ The acquiescence was an implicit yet powerful 'warrant' for new parents to select formula as nutritional baby food, as breastfeeding was not strongly supported by commercial forces, government regulations and medical practices. ${ }^{31}$ Therefore the messages of food safety and quality, mediated through the image of scientists, and the associated scientific benefits in the advertisements, were reinforced by medical professionals' implicit endorsement. Meanwhile, and regardless of their social backgrounds, parents from the younger generation frequently rely on the Internet to seek for information on childcare, thanks to the diffusion of computers and the Internet among households in urban China. Their social backgrounds only seem to have played a limited role in their ability to critically engage with the message of science in infant formula advertising. ${ }^{32}$ Their online activities are generally more empowering, including participating in discussion forums, searching for news on suspect infant formula brands and sharing their own experiences, often motivated by their determination to find alternative information as the state media do not always promptly expose food safety scandals when they are entangled with political interests. ${ }^{33}$ Mothers who participated in peer-support groups reported that they found useful information from online and offline meetings (e.g. how to care for toddlers with a slight fever), which demonstrated their skilful exploration of new media to engage with other new mothers who also lacked confidence in childrearing. More importantly, such active and public-minded activities may empower new parents with more choice and information, potentially giving rise to citizen-consumers who can exercise more political power in the marketplace.

\section{Consuming Science, Managing Risk}

The representation and consumption of 'science' were also located within discourses of health risk and consumer protection. In a health promotion video produced by a Chinese dairy company, for example, parents are told that pneumococcus poses serious threats to children under the age of two. ${ }^{34}$ In the course of the video, babies and young children are shown with a shining outline (halo), indicating the enhanced protection provided by artificially-added nutrients. The international company Dumex goes further to make 
'immufortics' into the shape of a shield, a visual signifier of health protection. ${ }^{35}$ These representations offer parents a strong form of psychological reassurance in addition to the assurance of food safety through the representations of nature described above. Infant formula advertisements emphasize the protective functions of the product by claiming that it boosts children's immune system. The wider context of the need for such protection is the general sense of 'risk', 'caution' and 'fear' felt by new parents in China. A recurring theme in our focus group discussions was that parents and other baby carers were generally anxious about the health of their children. One extreme example is of a mother who paid to store her umbilical cord blood in a medical bank for 20 years as a precaution against unlikely future genetic disorders for her daughter. ${ }^{36}$ She believed that this preventative measure served as a form of technical 'insurance' against future serious diseases for her daughter. In addition, the commercial blood bank actually provided health insurance as part of the service package for her baby:

The blood bank also gives her [daughter] health insurance for free every year. So if we don't use the blood, the money we pay for the storage buys her an insurance that covers $¥ 5000$ worth of serious disease treatment fees every year... (Mother from middle class background, group 12).

The 'double' insurance bought by this mother provides evidence of the extent of fear experienced by new parents in China. This mother's anxieties are rooted in the increasing costs of health care in China (Wagstaff et al, 2009). Despite the fact that infant care has improved greatly over the past decade, parental fears persist and provide fertile ground for commercial exploitation. In China particularly, parental confidence has been significantly undermined by the neoliberal reforms of the medical system and by recent food scares, including the 2008 infant formula scandal, leaving parents without independent and authoritative guidance on childcare issues. In some cases, too, doctors respond to the economic incentives of over-treatment, further exacerbating parental fears:

You have to listen to what the doctor says... If you don't take this treatment [IV drops] for a cold, they'll tell you that your child will develop this and that condition, and they sounded very scary (Grandmother from low-income background, group 3).

I spent $¥ 8000$ on treating my son’s jaundice at an intensive care unit. I should have listened to my mum. It only costs less than a hundred Yuan to cure this with phototherapy. But doctors said it was so serious, and I was totally scared. (Mother from middle class background, group 5). ${ }^{37}$

The frequency of post-natal health checks in China and warnings issued by doctors increase levels of anxiety among many new parents. This may prompt them to take more preventative measures such as the 'double insurance' discussed above. Recourse to preventative measures is also reflected in our participants' use of the immunisation system. Spread over two years, the immunisation system requires hospital visits every one or two months for children under the age of two. Most children are given over 20 vaccines (mandatory and elective). ${ }^{38}$ While many parents on lower incomes struggle to pay for the elective vaccines, many others are scared of the alleged consequences of not having them: 
[We get the jab] at the community hospital. If you don't go there, they [doctors] will scare you - that you'll get this and that disease. You don't want anything bad to happen to the kid, do you? (Grandmother from low-income background, group $3)$.

Our focus group discussions with young mothers show a pronounced sense of anxiety about the external world that may threaten the well-being of their children. These anxieties are then taken up by the infant formula companies, adopting the discourse of scientific and protective childcare in their advertisements. This may also explain why many new parents are susceptible to these discourses.

A more positive interpretation of these 'coping strategies' is that they demonstrate a citizen dimension in public life in a more general way. In the current neoliberal context, parents have started taking issues into their own hands, acting as members of a community with shared interests. As demonstrated above, our focus group participants raised issues of responsible parenting and trust in society at large. While some took a more proactive and individual approach to manage the food safety issue - taking advantage of the internet to search for more information and participating in peer support groups -- others openly voiced their high expectations of government regulation and the intervention of local community organizations:

The government should pay more attention and enhance its supervision.

At the end of the day this country depends on the next generation. Special attention should be given to the next generation in terms of food safety. Community committee and residential committee can start up some organizations, or find some people to advocate for food safety and supervision to get everyone's attention. Things will become better. (Grandmothers from low-income background, group 4)

Although public outrage over the food scare and concern about food safety after the infant formula scandal sped up the publication of the new Food Safety Law with more comprehensive and stricter food safety standards (Interview with office chief of China National Center for Food Safety Risk Assessment, 2010), critics suggest that consumer rights in China have still not received adequate protection due to the undemocratic and corrupt political system, as demonstrated in the cover-up of the infant formula scandal, suppressed media supervision, and unresolved victim compensations (Ye and Pang, 2011: 258). Corruption at local government level not only resulted in a series of food scares with lowlevel punishment (e.g. Fuyang infant formula scandal 2004) in China over the past ten years, but also led to rapidly declining public confidence in food safety authorities. However, corruption at the local level, manifested in the orchestrated cover-up between the local authority and Sanlu in 2008, deeply worries the central government which has been experiencing a 'legitimacy crisis' since the intensification of economic reform in 1992 (Shue, 2004). Public discontent over unemployment, expensive health care and income inequality resulting from the neoliberal reform poses a threat to the legitimacy of the Chinese Communist Party. To address the 'legitimacy crisis' the central government has extended its 
'benevolence', one of the 'key logics of legitimation in China' (Gries and Rosen, 2004: 9), through its efforts to improve the well-being of the people. Positioned at the centre of people's well-being, food safety issues have been given high priority as several new laws and regulations have been published, although their implementation at the local level is still being questioned (Ni and Zeng, 2009).

\section{Conclusion}

After the 2008 infant formula scare in China, infant formula companies created aggressive campaigns to communicate food safety messages to consumers. In this paper we have focused particularly on the representation and consumption moments in the 'circuit of culture' to understand how food safety and food quality messages were encoded and decoded in these two moments. We have shown how the dairy industry juxtaposed images of science and nature as part of their advertising campaigns to mediate messages about the quality and safety of infant formula. While the combination of 'nature' and 'science' may not sit so easily together in other contexts, these apparently disparate images were seamlessly combined in the case of infant formula advertising in China. Our focus group evidence shows that Chinese consumers engaged critically with representations of 'nature' in these advertisements, and that their decoding of these messages was shaped by their prior experiences (including their differentiation of nature in the Chinese and foreign contexts, their childhood experience and knowledge of rural environments). While some consumers were ambivalent towards the way 'science' is represented in the advertisements, including the dubious health claims and childcare advice offered by some brands in their promotional strategies, most were less unlikely to challenge the role of 'science' in contemporary childcare. However, the development of Information and Communication Technologies (ICTs), especially the diffusion of the Internet among urban consumers in China, has shifted the balance of power towards the audience. As discussed in this paper, there has been a critical engagement of the media by some parents, in particular parents from the younger generation, who have empowered themselves with the knowledge disseminated on the Internet and with their interactions with peer groups. Accompanying this is the rising trend of public-minded citizenconsumers who demand not only ethical practices in the infant formula industry, but also more accountability and transparency in government regulation. However, the government's response to these public demands is undermined by the corruption and non-transparency of the political system.

The high level of acceptance of science among consumers should be understood in a context where neoliberal healthcare reforms are increasing the cost of medical treatment and where reliable and independent sources of childcare advice are not readily available. These wider issues, such as neoliberal healthcare reform and the medicalization of childcare, we argue, underlie the representation and consumption of food safety and food quality messages. We conclude that, in the absence of independent medical advice, affordable medical treatment and adequate government regulation, infant formula companies will continue to be able to make ill-founded health claims for their products and employ dubious promotional tactics. Judging by recent market reports, however, these strategies appear to have had the desired effect as sales of infant formula have quickly returned to their pre-2008 levels (Qiao, et al., 
2010) although the balance between domestic and imported brands may have altered in favour of the latter.

Emphasising the critical analysis of advertising imagery and audience reception, this paper has offered limited insights into other aspects of the 'circuit of culture' such as the production processes involved in creating these advertisements. Further research is required to provide a more comprehensive understanding of the whole 'circuit' involved in producing, distributing and consuming infant formula advertising messages in China.

Notes

$1 \quad$ Our research is funded by information withheld to facilitate blind review.

Other family members such as aunts are also occasionally involved in baby care.

Commercial mass media advertising on the radio and billboards has existed in Shanghai since the 1920s (Prendergast and Shi, 2001). Communist China was hostile towards advertising, but relied heavily on it for political propaganda. During the Great Famine (1958-1961) and the Cultural Revolution (1966-1976), the government managed livelihood goods such as food and clothing based on rationing while denouncing advertising as a 'bourgeois capitalist vice' (Hong, 1994).

$4 \quad$ Permission for media institutions to carry advertisements was not only the result of the Open Door policy, but also an incentive for the state-funded media to seek alternative funding revenue (Paek and Pan, 2004: 494). In return, commercially-funded media outlets facilitated the 'revival' of advertising based on their wider reach of the Chinese public after the funding structure reforms (Hong, 1994).

5 The increasing income of urban residents is also noticeable: per capita annual income and per capita annual consumption expenditure have risen from $¥ 1,516$ and $¥ 1,278$ in 1990 to $¥ 14,908$ and $¥ 9,997$ in 2008 respectively (China Statistics Yearbook, 2009).

$6 \quad$ Young people are more likely to respond to symbolic images than the older generation; consumers in the hinterland are more responsive to the rational approach than their coastal counterparts; Shanghai prefers Pepsi while Beijing prefers Coke (Sinclair, 2008).

7 We used the keyword '奶粉 (milk powder)' to search the videos. In Chinese, infant formula is usually called '(baby) milk powder'. During the manual search, milk formula advertisements for adults (e.g. pregnant women and seniors) were excluded.

$8 \quad$ These variables include: Nature (farm, cow, etc.); Science and Technology; Assurance of safety and quality (institutional, organisation, etc.); Assurance of safety and quality(personal testimony); Aspiration (success, achievement, etc.); Nutritional and health benefits; Foreign ownership; Gender of care provider (mother, father, mother \& father); Family (nuclear, extended); Digestion and dissolvability; Green, organic; Specially designed for Chinese babies; Protection; Goat milk; Parental love; Charity, public interest; Responsibility, dedication; N/A; Other.

$9 \quad$ Here we present a simple frequency table, using statistics extracted from the analysis. We hope to develop the coding scheme further in future research to allow more advanced statistical analysis with SPSS.

10 The nature of our focus group method does not allow us to discuss how the decoding process is shaped by the demographic background of the audience in a more systematic way, given the relatively small number of participants (57) involved in the research.

11 Although the Chinese government has been tightening up the regulation of infant formula marketing in recent years, its key regulation 'The National Provisions on Marketing of Breast-Milk Substitutes' (see http://www.gov.cn/banshi/2005-08/23/content 25511.htm) promulgated on 1 
October 1995 was criticised for having had little effect on promoting breastfeeding. Gottschang's (2000) study found that new mothers received infant formula samples at the hospital, although the Provisions strictly forbid this. Receiving an infant formula sample was also widely reported by focus group participants in our study. Gottschang (2000: 277) argues that the illegal practice of promoting infant formula is insufficiently tackled by the government as the 'attractions of foreign investment and profit seeking have overcome the government's reluctance to produce and promote infant formula'. In addition to the Provisions, more detailed regulation on infant formula advertising in various media is regulated by the Chinese Advertising Association’s ‘Infant Formula Advertising Self-regulation’. This self-regulating document is helpful for promoting breastfeeding (e.g. it prohibits advertisers from using the image of new-born babies), but the regulation still needs further development (e.g. it does not regulate the frequency of broadcasting of advertisements) (see http://www.breastfeeding.com.cn/newsshow.asp?id=119\&big=3).

$12 \quad$ Permission has been acquired from Wondersun to use screenshots (in Figures 1 and 2) from their advertisements.

13 Mo liang xin 'Touch the heart (with the hand)' is a phrase in Chinese meaning 'with absolute sincerity and honesty'. This phrase is usually followed by a speech or an action. The 'hand-over-chest' gesture in Figure 2 could therefore be understood as a supporting statement to the 'conscience' claim of the advertisement. In Chinese, 'conscience' is translated into liang (good) xin (heart).

14 While the urban middle classes are appreciating more organic, green and slow-grown food, for many of them the 'reappraisal' also has a strong association with personal nostalgia: 17 million zhiqing (rusticated or educated youth) were displaced from their families and sent to rural villages or state farms, sometimes far away across the country, from the 1950s to 1976 (Yang, 2009). 15 According to Hubbert (2007: 95), as the Chinese Communist Party hesitates to officially acknowledge the trauma for the 17 million zhiqing, they use Culture Revolution themed restaurants which usually serve coarse food as a semi-public space to collectively recognise and memorialise their past suffering.

16 In China, as in the West, the contemporary consumption of nature is located within a neoliberal framework in which nature is increasingly being considered as a valuable existence that has a price. Coinciding with other neo-liberal trends in medical care to which we will turn in the second half of the paper, these rural gardens (run by private entrepreneurs) are encouraged by local government for creating jobs and generating tax revenue. Despite the lack of explicit government regulation of public resources such as lakes and mountains, the flourishing of such small-scale tourism has created a de facto market environmentalism in China as 'markets in environmental services are becoming the dominant approach to managing and protecting the environment in the twenty-first century' (Liverman, 2004: 735).

$17 \quad$ 'Foreigners' are usually represented by white characters.

18 The distinction between domestic and foreign brands is, in any case, becoming more complicated as foreign companies may franchise the production of infant formula in China to local (Chinese) companies (authors, in press).

19 We were unable to obtain permission from Firmus to use their advertising images in our paper. Due to copyright restrictions, the images cannot be displayed here but the video clip of this advertisement can be viewed at: http://v.youku.com/v show/id XODA4NTU0OTI=.html.

20 Other numbers and texts in these frames say: 300,000 purifying procedures with international standards, $3000 \mathrm{Mu}$ (494 Acre) Firmus farms at a latitude of $47^{\circ} \mathrm{N}$, attention of $280 \mathrm{R} \& \mathrm{D}$ staff members, and 47 years' dedication.

$21 \quad$ The science and technology development strategy dates back to the early history of the People's Republic of China founded in 1949. It accelerated with the assistance of the Soviet Union in 
the 1950s and 60s. The strategy stagnated in the 1960s and 1970s due to the withdrawal of Soviet experts and the Cultural Revolution, but continued throughout the late 1970s until the beginning of 2000. Since 2002, President Hu Jintao began promoting 'scientific development' alongside the 'harmonious society'. The current government's strategy calls for 'China's shift towards more balanced and more sustainable modes of development' (Wang, 2007: 78), in contrast to the economically-orientated scientific development strategy of previous governments.

22 The World Bank has reported how low-income TB victims failed to enter treatment or dropped out early due to the prohibitive fees (Liu and Mills, 2002: 1695).

23 Our focus group participants reported that all mandatory and elective vaccines cost more than $¥ 10,000$ for each child.

$24 \quad$ Previous research shows that 'technology', 'quality' and 'science' were dominant motifs in TV advertisements in China in 1980s and 1990s (Cheng, 1997).

25 Parents rely on frequent health checks at the hospital to confirm there is no food safety threat to their children.

$26 \quad$ For example, even though the European Parliament only cleared the way for infant formula companies to make health claims about Docosahexaenoic acid (DHA) based on scientific evidence following an application submitted by Mead Johnson Nutritionals in April 2011, the function of DHA in facilitating brain development had already become a central feature in almost all infant formula products in China by 2010 when the fieldwork for this research was carried out.

$27 \quad$ Arachidonic acid (ARA) and Docosahexaenoic acid (DHA). The scientific basis of the EU's resolution allowing infant formula companies to claim the health benefits of DHA is contested (scientific opinion published in the EFSA journal (2009) 1000, 1-13).

$28 \quad$ Abbott (China) is one of the most recognisable infant formula brands in China. Its parent company is Abbott Laboratories, a pharmaceutical company based in the US.

29 The video was full of warnings that parents should immunise their children against various diseases or risk them developing serious medical conditions.

$30 \quad$ For instance, patients' phone numbers were often leaked to infant formula sales representatives from these hospitals; formula company-sponsored seminars were also held in some of the hospitals at community level.

31 Other factors such as weak law enforcement, poor arrangement of maternity leave, and heavy reliance on grandparents to provide childcare for new-born babies all contributed to decreasing rates of breastfeeding. See authors (in press).

32 A mother with a Master's degree in one of the 'middle class and above' groups is the only participant who understood the full name of DHA after she did research on the Internet, but she did not question the health benefits of DHA claimed by infant formula advertisements. See note 25 . Other parents in lower income groups, although not knowing the full name of DHA, also thought DHA was a must-have nutrient for infant formula.

33 Jian Guangzhou, the first Chinese journalist who blew the whistle on Sanlu infant formula in Oriental Morning newspaper in 2009, was under tremendous pressure when he was investigating the scandal which was link to the political interests of the local government. Jian resigned from his position in September 2012. See 'Jian Guangzhou: Why I spoke up about Sanlu' from http://news.qq.com/zt/2008/dialog/jgz.htm; Ye and Pang, 2011; http://media.nfdaily.cn/h02/content/2012-09/05/content_54339899.htm)

34 According to this video, possible diseases caused by pneumococcus include pneumonia, meningitis, otitis media, bacteremia, hypophrenia, deafness, epilepsy and paralysis. The video also claims that pneumococcus infection results in 0.7 to 1 million child deaths each year worldwide. 
35 See links to the ads here: $\underline{\text { http://v.youku.com/v show/id XMjczOTA3NjQw.html; }}$ http://v.youku.com/v_show/id_XNzIwNjE2MDA=.html

35 Only a small percentage of babies (estimated at between 1:1,000 to 1:200,000) ever use the umbilical cord blood that is stored (2007 'Policy Statement on Cord Blood Banking', The American Academy of Pediatrics).

36 The WHO criticised China's health care system for its supply-induced demand, particularly for inpatient services. According to one report: 'Irrational use of health technologies, such as prescribing unnecessary diagnostic tests and medicines, and referring more patients for hospital admissions are ... part of revenue-driven approaches used by the Chinese service providers to make more money that can be used to increase the income level of doctors and other staff' (http://www.who.int/bulletin/volumes/86/11/08-011108/en/, accessed on 15 July 2011).

37 This can be compared with the single six-in-one jab that toddlers are given at one year old in the UK.

\section{References}

Anderson M (1981) ‘China’s Great Leap towards Madison Avenue’, Journal of Communication 31 (4): $10-22$.

Ang I (1991) Desperately Seeking the Audience. London: Routledge.

Ang I (1996) Living Room Wars: Rethinking Media Audiences for a Postmodern World. London: Routledge.

Apple R (1987) Mothers and Medicine: a Social History of Infant Feeding 1890-1950. Madison, Wisconsin: University of Wisconsin Press.

Apple R (2006) Perfect Motherhood: Science and Childrearing in America. New Brunswick, New Jersey: Rutgers University Press.

Bakker K (2010) 'Neoliberalising Nature? Market Environmentalism in Water Supply in England and Wales', Annals of the Association of American Geographers 95(3): 542-565.

Chan K (1997) 'Creating Advertising that Appeals to Chinese Women', Asian Journal of Communication 7(1): 43-57.

Chan K and Chan F (2005) 'Information Content of Television Advertising in China: An Update', Asian Journal of Communication 15(1): 1-15.

Cheng H (1994) 'Reflections of Cultural Values: A Content Analysis of Chinese Magazine Advertisements from 1982 and 1992', International Journal of Advertising 13(2): 167-83.

Cheng H (1997) 'Toward an Understanding of Cultural Values Manifest in Advertising: A Content Analysis of Chinese Television Commercials in 1990 and 1995’, Journalism Quarterly 74(4): 77396.

Cheong Y, Kim K and Zheng L (2010) 'Advertising Appeals as a Reflection of Culture: a Crosscultural analysis of Food Advertising Appeals in China and the US', Asian Journal of Communication 20(1): 1-16.

Cheong Y, Zheng L and Kim K (2011) 'Product Global Reach, Advertising Standardization, and Cultural Values: An Analysis of 2008 Beijing Olympic TV Commercials', Asian Journal of Communication 21(3): 279-300.

China Statistics Yearbook (2009) Total Population by Urban and Rural Residence and Birth Rate, Death Rate, Natural Growth Rate by Region, Basic Conditions of Urban Households [In Chinese] Available at: http://www.stats.gov.cn/tjsj/ndsj/2009/html/D0304e.htm and http://www.stats.gov.cn/tjsj/ndsj/2009/html/J0905e.htm (accessed 15 June 2010) 
Cross G (2004) 'Wondrous Innocence: Print Advertising and the Original of Permissive Child Rearing in the US', Journal of Consumer Culture 4(2): 183-201.

Curtis K, Mccluskey F and Wahl T (2007) 'Consumer Preference for Western-style Convenience Foods in China', China Economic Review 18: 1-14.

Davis D and Sensenbrenner J (2000) 'Commercializing Childhood: Parental Purchase for Shanghai's Only Child', in Davis D (ed.) The Consumer Revolution in Urban China. Berkeley, Los Angeles and London: University of California Press, 54-79.

du Gay P, Hall S, Janes L, Mackay H. and Negus K (1997). Doing cultural studies: The story of the Sony Walkman. London: Sage.

Descola P and Palsson G (eds) (1996) Nature and Society: Anthropological Perspectives. London: Routledge.

Dimitri C and Oberholtzer L (2010) 'Marketing U.S. Organic Foods: Recent Trends from Farms to Consumers', USDA Economic Information Bulletin. 58: 1-27.

Domosh M (2003) 'Pickles and Purity: Discourses of Food, Empire and Work in Turn-of-century USA', Social \& Cultural Geography 4(1): 7-26.

Donald S, Keane M and Hong Y (eds) (2002) Media in China: Consumption, Content and Crisis. London: Routledge.

Du J (2009) 'Economic Reforms and Medical Insurance in China', Social Science \& Medicine 69(3): 387-95.

Equi Media (2011) China Challenges Top Stop for Ad Spending. Available at: http://www.equimedia.co.uk/index.php?id=98\&article=800696932, (accessed 12 August 2011)

Farquhar J (2002) Appetites: Food and Sex in Postsocialist China. Durham, NC; London: Duke University Press.

Ferry M (2003) 'Advertising, Consumerism and Nostalgia for the New Woman in Contemporary China’, Continuum: Journal of Media \& Cultural Studies 17 (3): 277-290.

Fung A (2009) 'Fandom, Youth and Consumption in China', European Journal of Cultural Studies 12 (3): 285-303.

Gerard P and Shi Y (2001) 'Client Perceptions of Advertising and Advertising Agencies: a China Study’, Journal of Marketing Communications 7(2): 47-63.

Authors

Gottschang S (2000) 'A Baby-Friendly Hospital and the Science of Infant Feeding', in Jing J (ed.) Feeding China’s Little Emperors. Stanford, California: Stanford University Press, 160-84.

Gottschang, S (2000) 'Reforming Routines: A Baby-Friendly Hospital in Urban China', in Whiteford, L and Manderson L (eds.) Global Health Policy Local Realties: The Fallacy of the Level Playing Field. Boulder and London: Lynne Rienner Publishers, Inc., 265-290.

Grant J (1998) Raising Baby by the Book: the Education of American Mothers. New Haven, Connecticut: Yale University Press.

Green J, Draper A and Dowler E (2003) 'Short Cuts to Safety: Risk and 'Rules of Thumb' in Accounts of Food Choice’, Health, Risk \& Society 5(1): 33-52.

Griffiths M, Chapman M and Christiansen F (2010) 'Chinese Consumers: The Romantic Reappraisal', Ethnography 11(3): 331-57.

Gunter B, Hansen A and Touri M (2010) Alcohol Advertising and Young People's Drinking: Representation, Reception and Regulation. Basingstoke: Palgrave Macmillan.

Hall S (1980) 'Encoding/decoding' in Hall S (ed.) Culture, media, language. London: Hutchinson, 128-138.

Hall S (ed.) (1997) Representation: Cultural Representations and Signifying Practices. London: Sage. Harvey D (2005) A Brief History of Neoliberalism. Oxford: Oxford University Press. 
Hays P and Rosen S (2004) 'Introduction: Popular Protest and State Legitimation in $21^{\text {st }}$-century China’, in Hays P and Rosen S (eds.) State and Society in $21^{\text {st }}$ Century China. London: Routledge, $1-23$.

Holland A (1999) Voices of Qi: an Introductory Guide to Traditional Chinese Medicine. Berkeley: North Atlantic Books.

Hollander G (2003) 'Re-naturalizing Sugar: Narratives of Place, Production and Consumption’, Social \& Cultural Geography 4(1): 59-74.

Hong J (1994) 'The Resurrection of Advertising in China: Developments, Problems, and Trends', Asian Survey 34(4): 326-42.

Hopkins B (2010) 'Western Cosmetics in Gendered Development of Consumer Culture in China' in:

Berik G, Dong X and Summerfield G. (eds.) Gender, China and the World Trade Organisation. London, New York: Routledge, 282-301.

Hubbert J (2007) 'Serving the Past on the Platter: Cultural Revolution Restaurants in Contemporary China' in: Beriss D and Sutton D (eds.) The Restaurant Book: Ethnographies of Where We Eat. Oxford, New York: Berg, 79-96.

Ingram M (2007) 'Biology and Beyond: The Science of "Back to Nature” Framing in the United States', Annals of the Association of American Geographers 97(2): 298-312.

Klein J (2006) 'Changing Taste in Guangzhou: Restaurant Writings in the late 1990s', in: Latham K, Thompson S and Klein J (eds.) Consuming China: Approaches to Cultural Changes in Contemporary China. Oxon and New York: Routledge, 104-120.

Latham K (2006) 'Introduction: Consumption and Cultural Change in Contemporary China', in: Latham K, Thompson S and Klein J (eds.) Consuming China: Approaches to Cultural Changes in Contemporary China. Oxon and New York: Routledge, 1-21.

Liu X (2004) 'Han', in: Ember C and Ember M (eds.) Encyclopaedia of Medical Anthropology: Health and Illness in World's Cultures. New York: Kluwer Academic/Plenum Publishers, 703-17. Liu X and Mills A (2002) 'Financing Reforms of Public Health Service in China: Lessons for other Nations', Social Science \& Medicine 54 (11): 1691-1698.

Liverman D (2004) 'Who Governs, at What Scale and at What Price? Geography, Environmental Governance, and the Commodification of Nature', Annals of the Association of American Geographers 94(4): 734-38.

Matthews J, Gunter B and Dickinson R (2009) 'The Nature of Infant Formula and Follow-on Formula Advertising and Presentation', Report for Food Standards Agency. Available at: http://www2.le.ac.uk/departments/media/documents/375-1-653-Research-project-1-report-forpublication-September-09.pdf (accessed 15 July 2011).

Morley D (1980) The 'Nationwide' Audience. London: British Film Institute.

Morley D (1992) Television, Audiences and Cultural Studies. London: Routledge.

Nelson M (2010) Parenting Out of Control: Anxious Parents in Uncertain Times. New York and London: New York University Press.

Ni H and Zeng H (2009) ‘Law Enforcement is Key to China’s Food Safety’ Environmental Pollution 157: 1990-1992.

Nicholas D (2011) Technology of Bottled Water, 3rd edition. Oxford: Wiley-Blackwell.

Nielsen Media Research (2006) News flash: Chinese Advertising Market Review 1st Quarter 2006. Available at: http://www.amcham-china.org.cn/amcham/upload/wysiwyg/20060620144824.pdf (accessed 10 August 2011).

Paek H and Pan Z (2004) 'Spreading Global Consumerism: Effects of Mass Media and Advertising on Consumerist Values in China', Mass Communication and Society 7(4): 491-515.

Paterson M (2006) Consumption and Everyday Life. London and New York: Routledge. 
Pei X, Tandon A, Alldrick, A, Giorgi, L, Huang, W and Yang R (2011) 'The China Melamine Milk Scandal and Its Implications for Food Safety Regulation’, Food Policy 36 (3): 412-20.

Qiao G, Guo T and Klein K (2010) 'Melamine in Chinese Milk Products and Consumer Confidence', Appetite 55(2): 190-195.

Sayer A (2003) ‘(De)commodification, Consumer Culture, and Moral Economy’, Environment and Planning D: Society and Space 21(3): 341-57.

Schroder, K. C. (2000) 'Making sense of audience discourses: Towards a multidimensional model of mass media reception’, European Journal of Cultural Studies 3 (2): 233-258.

Shi X (2009) 'A Comparative Analysis of Systematic Management of Infant Physical Development in 1995 and 2005', Maternal and Child Health Care of China 24(10): 1316-1317.

Shue V (2004) 'Legitimacy Crisis in China?', in Hays P and Rosen S (eds.) State and Society in $21^{\text {st }}$ Century China. London: Routledge, 24-49.

Silverstone R and Hirsch E (eds.) (1992) Consuming Technologies: Media and Information in Domestic Spaces. London: Routledge.

Sinclair J (2008) ‘Globalization and the Advertising Industry in China', Chinese Journal of Communication 1(1): 77-90.

Stearns P (2003) Anxious Parents: a History of Modern Childrearing in America. New York: New York University Press.

The Central People's Government of the People's Republic of China (1995) Codes of Sale of Breastmilk Substitute. Available from http://www.gov.cn/banshi/2005-08/23/content_25511.htm/ (Accessed September 11 2012)

The China Advertising Association (2009) Infant Formula Advertising Self-Regulation. Available from http://www.cnadtop.com/confraternityIntro/2009/2/9/210f2e98-5fe1-499c-b9b4229f041c9028.htm. (Accessed September 11 2012)

Wagstaff A, Lindelow M, Wang S and Zhang S (2009) Reforming China's Rural Health System. Washington D.C.: the World Bank.

Wang J (2003) 'Framing Chinese Advertising: some Industry Perspectives on the Production of Culture', Continuum: Journal of Media and Cultural Studies 17(3): 247-60.

Wang Z (2000) Foreign Advertising in China. Ames, Iowa: Iowa State University Press.

Wang Y (2008) Brand New China: Advertising, Media and Commercial Culture. Cambridge, MA: Harvard University Press.

Wang Z (2007) 'What to Expect from the $17^{\text {th }}$ Party Congress?' in: Wang G and Wong J (eds.) Interpreting China's Development. Singapore: World Scientific Publishing, 77-82.

Wei R (2002) 'Embracing Advertising: Chinese Consumers Show a New Attitude in the 1990s', Journal of Asian Communication 12(1): 58-76.

Wilk R (2006) 'Bottled Water: the Pure Commodity in the Age of Branding', Journal of Consumer Culture 6(3): 303-325.

Williams R (1973) The Country and the City. Oxford: Oxford University Press.

Wood L and Kroger R (2000) Doing Discourse Analysis: Methods for Studying Actions in Talk and Text, Thousand Oaks, London and New Delhi: Sage Publications.

Xu F, Liu X, Binns C, Xiao C, Wu J and Lee A (2006) 'A Decade of Change in Breastfeeding in China's Far North-West', International Breastfeeding Journal 1(22): 1-7.

Xinhua News Agency (2008) 婴幼儿配方奶粉三聚氧胺专项检查阶段性检查结果公布 [Results of Inspection of Melamine in Infant Formula _In Chinese] Available from: http://news.xinhuanet.com/newscenter/2008-09/17/content_10047162.htm (accessed July 15, 2010) 
Yan Y (1997) 'McDonald's in Beijing: The Localization of Americana', in: Watson J (ed.) Golden Arches East McDonald's in East Asia. Stanford: Stanford University Press, 39-76.

Yang B (2009) "“We Want to Go Home!” The Great Petition of the Zhiqing, Xishuangbanna, Yunnan, 1978-1979’, China Quarterly 198: 401-421.

Ye L and Pang A (2011) 'Examining the Chinese Approach to Crisis Management: Cover-Ups, Saving Face, and Taking the "Upper Level Line”' Journal of Marketing Channels 18(4): 247-278.

Zhang C, Bai, J, Lohmar, B and Huang J (2010) 'How do consumers determine the safety of milk in Beijing, China' China Economic Review 21: S45-54.

Zhao Y (2008) Communication in China: Political Economy, Power and Conflict. Lanham: Rowman \& Littlefield.

Zhou D, Zhang W and Vertinsky I (2002) 'Advertising Trends in Urban China’, Journal of Advertising Research 42(3): 73-81.

Zhou, L. and Hui, M. K. (2003) 'Symbolic Value of Foreign Products in the People's Republic of China', Journal of International Marketing 12 (2): 36-58.

Zhou X (2008) 'Chinese Middle Class: Reality or Illusion?’ in: Jaffrelot C and Van der Veer, P (eds.) Patterns of Middle Class Consumption in India and China. New Delhi, Thousand Oaks and London: Sage, 110-126. 